\title{
Asociación entre porphyromona gingivalis y proteína C reactiva en enfermedades sistémicas inflamatorias ${ }^{1}$ \\ Association between porphyromonas gingivalis and $\boldsymbol{C}$-reactive protein in systemic inflammatory diseases
}

\author{
ARDILA MEDINA CM* \\ LAFAURIE VILLAIMIL GI**
}

\begin{abstract}
Ardila Medina CM, Lafaurie Villamil GI. Asociación entre porphyromona gingivalis y proteína $C$ reactiva en enfermedades sistémicas inflamatorias. Av Periodon Implantol. 2010; 22, 1: 45-53.
\end{abstract}

\section{RESUMEN}

La proteína C reactiva (PCR) es un marcador serológico de la inflamación asociado con incremento en el riesgo de enfermedades sistémicas inflamatorias (ESI). La periodontitis también se relaciona con niveles elevados de PCR en adultos y con una reducción de la misma después de su tratamiento. Así, se ha postulado que la PCR puede ser un posible mediador de la asociación entre periodontitis y ESI. Los patógenos periodontales además de inducir inflamación local y destrucción tisular están involucrados en el aumento de la respuesta sistémica inflamatoria e inmunológica. Diferentes autores han investigado la relación entre los anticuerpos para algunos patógenos periodontales y la PCR, pero la asociación se ha notificado firmemente para IgG a Porphyromona gingivalis. Es escasa la evidencia de asociación de una medida directa entre patógenos periodontales y PCR, sin embargo es muy importante debido a que la presencia de anticuerpos no necesariamente es un indicador de infección activa.

PALABRAS CLAVE: Proteína C reactiva, inflamación, periodontitis, porphyromona gingivalis.

\section{SUIMIMARY}

C-reactive protein (CRP) is a serological marker of systemic inflammation that has been associated with increased risk systemic inflammatory diseases. Periodontitis has also been linked to elevated CRP levels in adults as well as with a reduction in PCR after its treatment. It is thus postulated that CRP might be a possible mediator of the association between periodontitis and systemic inflammatory diseases. Periodontal pathogens do not induce only local inflammation and tissue destruction. They are also involved in systemic increases in inflammatory and inmmune responses. Several studies have investigated antibodies to various periodontal pathogens in relation to CRP, but the association has been reported consistently only for IgG to Porphyromonas gingivalis. Evidence is sparse on the association between a direct measure of periodontal pathogens and CRP, while it is more important because the presence of antibody titers is not necessarily indicative of an active infection.

KEY WORDS: C-reactive protein, inflammation, periodontitis, porphyromonas gingivalis.

Fecha de recepción: 5 de marzo 2009.

Fecha de aceptación: 14 de marzo 2009.

1 Trabajo derivado de investigación financiada por el Instituto Colombiano de Ciencia y Tecnología "Francisco José de Caldas" COLCIENCIAS ( $\left.{ }^{\circ} 1308-45-921661\right)$.

* Profesor Asistente Universidad de Antioquía. Candidato a PhD en Epidemiología.

** Directora Instituto de Investigación Básica Oral Universidad El Bosque. 


\section{INTRODUCCIÓN}

Diferentes estudios epidemiológicos concluyen que los pacientes con periodontitis presentan alto riesgo de padecer enfermedades sistémicas inflamatorias (ESI). La asociación puede estar ligada a efectos directos de los patógenos periodontales o a efectos indirectos mediados por el huésped y desencadenados por la infección. La infección periodontal se considera como una inflamación subclínica en la que se observa asociación con niveles elevados de proteína C-reactiva (PCR) y aumento en el riesgo de ESI (1). Sin embargo, otros marcadores inflamatorios sistémicos como el factor de necrosis tumoral a y la interleuquina-6 presentan resultados contradictorios (2). Diferentes investigadores demuestran una fuerte asociación entre el incremento de la PCR sérica y presencia de periodontopatógenos. Consecuentemente, algunos estudios in vitro indican que la Porphyromona Gingivalis (Pg) puede tener una relación con ESI, debido a que esta bacteria puede invadir las células endoteliales (3), y porque su polisacárido induce la adhesión de moléculas y la producción de citoquinas en las células endoteliales. La aparente especificidad de anticuerpos a Pg en la incidencia de ESI soporta la hipótesis en donde la infección con, o la respuesta del huésped a, esta bacteria específica es particularmente deletérea (4). Debido a que los periodontopatógenos comprenden diferentes bacterias heterogéneas genética y serológicamente, se puede especular que una o pocas especies pueden ser particularmente importantes en el desarrollo y progreso de ESI (5). El objetivo de este artículo es presentar la asociación entre Porphyromona Gingivalis y Proteína $\mathrm{C}$ reactiva, y sus implicaciones en enfermedades sistémicas inflamatorias.

\section{PORPHYROIMONA GINGIVALIS}

Pg es un anaerobio gram-negativo que constituye parte de la biopelícula subgingival madura, hace parte del llamado complejo rojo y es un colonizador exitoso de los tejidos orales (6). Se ha estudiado notablemente por su patogenicidad en una gran cantidad de estudios que involucran muchos tipos de células del huésped. Además de ser un factor de riesgo para EIS, este microorganismo se ha identificado también como factor de riesgo para infecciones pulmonares, parto pretérmino y bajo peso al nacer $(7,8)$. Una gran cantidad de publicaciones proponen que Pg produce varios factores de virulencia incluyendo proteasas extracelulares que pueden ocasionar modulación de la respuesta inmune, y adhesión/degradación de las proteínas ce- lulares del huésped y receptores de superficie (9); un lipopolisacárido único que interfiere con la respuesta inflamatoria del huésped vía inmunidad innata y adquirida (10); una invasina; y adhesinas tales como hemoaglutininas y fimbrias. Estas fimbrias han sido clasificadas en seis tipos (I a V y Ib), con base en la diversidad de los genes fimA (10). Algunos estudios demuestran que clones tipo II fimA presentan virulencia significativamente mayor in vitro e in vivo (10). Todos estos factores pueden favorecer la invasión exitosa de los tejidos del huésped (10). Como consecuencia, diferentes autores discuten las propiedades estructurales multifacéticas de la Pg con su potencial acción nociva contra varias células hospederas incluyendo macrófagos, neutrófilos, fibroblastos, células dendríticas, endoteliales, y células epiteliales orales y no orales (11). Pg es una de las bacterias asociadas con enfermedad periodontal detectadas en la placa aterosclerótica (4), sugiriendo que estos microorganismos pueden ser metabólicamente activos dentro de las lesiones ateroscleróticas, incrementando el riesgo para infarto del miocardio (3). Adicionalmente, anticuerpos séricos a Pg se asocian con diferentes ESI, estableciéndose que la infección con Pg induce inflamación local (3). La inducción de esta respuesta inflamatoria puede conducir a ulceración gingival y cambios vasculares locales que tienen el potencial de incrementar la incidencia y severidad de bacteriemias transitorias (12).

Diferentes estudios concluyen que los pacientes con enfermedad periodontal tienen niveles elevados de mediadores inflamatorios sistémicos. De esta forma, la enfermedad periodontal se asocia extensamente con niveles elevados de proteína C reactiva (PCR) (13), reconocida como una de las mayores proteínas de fase aguda, y un marcador sistémico de la inflamación documentado como factor de riesgo para ESI (13).

\section{PROTEINA C REACTIVA}

La PCR es el marcador más usado para la inflamación. Epidemiológicamente se vincula a: el estado nutricional y sus marcadores (14), enfermedad cardiovascular (15), morbilidad y mortalidad en pacientes con enfermedad renal crónica (16), artritis reumatoide (17), preeclampsia (18) y resultados adversos en el embarazo (19).

La PCR fue notificada inicialmente en 1930 cuando se advirtió un anticuerpo como la precipitina en respuesta al polisacárido C de la pared celular de Streptococcus pneumoniae; así, se originó su nombre como proteína $C$ reactiva (20). La $P C R$ es miembro de la familia 
pentraxina, término que refleja la estructura cuaternaria de la proteína, donde se combinan cinco unidades de protómeros idénticos para formar un anillo con núcleo hidrofóbico central (21).

El incremento en la concentración de PCR puede ser inespecífico y ocurre con varios estímulos, enfermedad o lesión, algunas veces dramáticamente y por encima de 1.000 a 2.000 veces (22). Bajo condiciones normales, la PCR es producida por los hepatocitos en una tasa baja y retenida posteriormente por el retículo endoplasmático antes de su secreción (23). Hasta hace poco, valores PCR menores a $10 \mathrm{mg} / \mathrm{l}$ eran considerados normales, sin embargo, en el $85 \%$ de los pacientes con infecciones bacterianas agudas se presentan valores mayores a $100 \mathrm{mg} / \mathrm{l}$, niveles que pueden predecir complicaciones ateroscleróticas (2). Actualmente, un nivel cercano a los $3 \mathrm{mg} / \mathrm{l}$ se considera adecuado, debido a que es mucho más exacto y altamente sensible a la inmunoturbidimetría o inmunonefelometría, métodos que permiten medir niveles mucho más bajos de PCR (24). Durante la respuesta de fase aguda, existe rápido incremento en la síntesis y liberación súbita de PCR (23). La tasa catabólica para la PCR es independiente de su concentración en el plasma, y los niveles séricos son muy dependientes de la tasa de síntesis $(23,24)$. Bajo condiciones estables la PCR no muestra variabilidad circadiana significativa y su estabilidad como medida de laboratorio es similar a la presentada por los niveles de colesterol en el suero (24). Todas estas características convierten la PCR en magnífico marcador de la inflamación con una respuesta biológica favorable y buenas propiedades analíticas (25). Sin embargo, otros factores también pueden incrementar los niveles basales de PCR, incluyendo testosterona, progesterona, administración de terapia hormonal por reemplazo, resistencia a la insulina, tolerancia a la glucosa, hábito de fumar y periodontitis (25).

\section{ESTUDIOS QUE RELACIONAN LA PORPHYROMONA GINGIVALIS Y LA PROTEÍNA C REACTIVA CON ENFERIMEDADES SISTÉMICAS INFLAIMATORIAS}

Una variedad de estudios abordan la asociación entre Pg y PCR como factores de riesgo para distintas enfermedades sistémicas inflamatorias: enfermedad cardiovascular, diabetes, enfermedad renal, artritis reumatoide, preeclampsia y resultados adversos en el embarazo.
La asociación potencial entre marcadores serológicos de la periodontitis y los factores inflamatorios relacionados mecánicamente al proceso de la aterosclerosis, asignan la proporción del riesgo total mediado por la infección para la enfermedad cardiovascular y eventualmente atribuida a la periodontitis. El primer informe que soportó la actividad metabólica de Pg en ateroma humano se realizó en dos pacientes con aterosclerosis, empleando la técnica de hibridación fluorescente in situ (FISH) (25). Sin embargo, en esa publicación el pequeño número de casos estudiados no permite llegar a conclusiones acerca de la correlación entre enfermedad periodontal y aterosclerosis. Por lo anterior, se han realizado diferentes investigaciones con el fin de dilucidar la asociación entre Pg y PCR, incluyendo estudios de base poblacional con individuos sistémicamente sanos o enfermos, y estudios en animales.

Pitiphat y cols. (2), realizaron una investigación para evaluar la asociación de la periodontitis crónica y Pg con PCR en adultos Thai saludables sistémicamente. La PCR fue medida en 21 sujetos con periodontitis generalizada, 62 con periodontitis localizada y un grupo control constituido por 38 pacientes sanos. Los individuos estudiados presentaron un nivel promedio de PCR inferior al observado en poblaciones occidentales. Los sujetos con periodontitis generalizada y localizada mostraron niveles promedio de PCR inferiores a los controles $(1,78$ y $0,65 \mathrm{mg} / 1$, y $0,25 \mathrm{mg} / \mathrm{l}$ respectivamente, $\mathrm{p}<0,001)$. Al ajustar por edad, índice de masa corporal y hábito de fumar, el modelo de regresión lineal multivariado mostró que el log para niveles de PCR se incrementó en los pacientes con periodontitis generalizada $(p<0,01)$ y localizada $(p=0,03)$. La presencia de Pg también se asoció con niveles aumentados de PCR $(p<0,001)$. Los autores concluyeron que la infección periodontal puede contribuir a cargas inflamatorias sistémicas en individuos saludables.

Otras investigaciones también han encontrado además de la correlación entre Pg y PCR, asociación con otros periodontopatógenos (26-28). Es así como, Lund Haheim y cols. (26), estudiaron las diferencias entre la asociación de bacterias individuales o combinación de ellas y su relación con PCR. Examinaron los niveles de anticuerpos para cuatro patógenos periodontales (Pg, Aggregatibacter actinomycetemcomitans (Aa), Tannerella forsythia, Treponema denticola) y PCR en 548 hombres con historia autoinformada de infarto del miocardio. Además, se incluyeron 625 controles que tomaron parte en el II estudio de Oslo. Los resultados mostraron niveles de anticuerpos elevados contra los periodonto- 


\section{TABLA 1.- ESTUDIOS QUE RELACIONAN LA PORPHYROMONA GINGIVALIS Y LA PROTEÍNA C REACTIVA CON ENFERIMEDADES SISTÉIMICAS INFLAMATORIAS}

\begin{tabular}{|lccc|}
\hline Estado sistémico & Tamaño de la muestra & Autor & Año \\
\hline Saludable & 121 & Pitiphat (2) & 2008 \\
\hline Infarto de miocardio & 1.173 & Lund Haheim (26) & 2008 \\
\hline Enfermedad cardiovasculares & 505 & Pussinen (27) & 2007 \\
\hline Enfermedad cardiovasculares & 174 & Noack (28) & 2001 \\
\hline Enfermedad cardiovasculares & 2.973 & Dye (29) & 2005 \\
\hline Respuesta de fase aguda & 185 & Craig (22) & 2003 \\
\hline Hipertensión & 1.314 & Furuichi (30) & 2003 \\
\hline Síndrome coronario agudo & 322 & Renvert (32) & 2006 \\
\hline Diabetes tipo 2 & 132 & Nishimura (34) & 2002 \\
\hline Diabetes tipo 2 & 134 & Taniguchi (35) & 2003 \\
\hline Diabetes tipo 2 & 134 & Kuroe (36) & 2004 \\
\hline Artritis reumatoide & 157 & Mikuls (17) & 2009 \\
\hline Preeclampsia & 398 & Herrera (18) & 2007 \\
\hline Amenaza parto prematuro & 26 & León (38) & 2007 \\
\hline
\end{tabular}

patógenos estudiados, encontrándose una asociación en donde se observó incremento en el riesgo relativo (RR) en un 30\% para infarto del miocardio. Una combinación de anticuerpos contra Pg, Aa y Treponema denticola, obtuvieron el mismo RR. Al ajustar por PCR no se alteraron las conclusiones y los casos tuvieron niveles más altos de PCR que los controles. Cuando en el análisis multivariado se incluyeron los factores de riesgo conocidos para infarto del miocardio, el RR cambió marginalmente. Esto demostró que los niveles de anticuerpos y las infecciones orales fueron independientes de los factores de riesgo comunes para predecir infarto del miocardio.

Pussinen y cols. (27), en un estudio prospectivo investigaron la asociación entre endotoxina sérica, anticuerpos a periodontopatógenos y marcadores inflamatorios, con el riesgo de incidencia en enfermedad cardiovascular. La cohorte FINRISK (Base poblacional con factores de riesgo para enfermedad crónica) de 1992 constituida por 6.051 individuos se siguió por 10 años. A partir de esta base poblacional, se examinaron 185 eventos cardiovasculares incidentes y una co- horte control de 320 individuos, empleando un diseño caso-cohorte prospectivo. Se encontraron altos niveles de anticuerpos tipo IgG a Pg y Aa. Además, una concentración alta de endotoxina sérica fue factor de riesgo para eventos cardiovasculares, independientemente de la edad y el sexo. Se observó un riesgo elevado principalmente en los casos, donde una respuesta inmune alta a Pg y Aa, o a concentraciones de endotoxinas, estuvieron acompañadas por una reacción inflamatoria, indicada por concentraciones elevadas de PCR. Interesantemente, estas asociaciones fueron específicas para eventos cardiovasculares.

Noack y cols. (28), evaluaron si se encontraban aumentados los niveles de PCR plasmáticos en la periodontitis y si existía una relación con la gravedad de la enfermedad periodontal y la microflora periodontopatógena. Los niveles de PCR fueron evaluados empleando un ensayo de inmunodifusión radial en 174 sujetos, 59 con pérdida de inserción moderada y 50 con pérdida avanzada, comparados con 65 individuos periodontalmente sanos. Se observó un incremento significativo en los niveles de PCR en los sujetos con 
periodontitis, cuando se comparaban con los controles $(p=0,036)$. Igualmente, los individuos con pérdida avanzada de inserción clínica presentaron niveles más elevados de PCR $(4,06 \pm 5,55 \mathrm{mg} / \mathrm{l})$ que los controles $(1,70 \pm 1,91 \mathrm{mg} / \mathrm{l})$ con valor $\mathrm{p}=0,011$. La presencia de Pg, Prevotella intermedia y Tannerella forsythia fue asociada positivamente con niveles elevados de PCR $(p=0,029)$. Los autores concluyeron que la correlación positiva entre algunos periodontopatógenos y PCR puede ser una posible vía subyacente en la asociación observada entre periodontitis y alto riesgo a enfermedad cardiovascular.

A pesar de los hallazgos de las investigaciones realizadas por Lund (26), Pussinen (27) y Noack (28), existen otras investigaciones que demuestran la falta de asociación entre PCR y otros periodontopatógenos distintos a Pg $(22,29,30)$, corroborando de esta manera los resultados encontrados por Pitiphat (2). Dye y cols. (29), emplearon datos de una muestra representativa poblacional (NHANES III) constituida por 2973 participantes mayores de 40 años con información periodontal clínica. Examinaron la relación entre la respuesta de la IgG sérica a Pg y Aa, y dos proteínas inflamatorias importantes (PCR y fibrinógeno), con el fin de evaluar su capacidad para predecir aterosclerosis y eventos cardiovasculares e isquémicos. Se emplearon tres modelos de regresión logística ajustados por género, raza, nivel educativo, diabetes, hábito de fumar, índice de masa corporal y otras condiciones inflamatorias, con base en tres diferentes supuestos: no acceso a información periodontal, conocimiento del número de dientes presentes pero no del estado periodontal y conocimiento del estado dental/clínico periodontal. Se relacionó una PCR elevada $(>0,4 \mathrm{md} / \mathrm{dl})$ con niveles altos de anticuerpos a $\mathrm{Pg}$ en el primer modelo [odds ratios (OR) 1,63, intervalo de confianza (IC) del 95\% $1,15-2,32]$. En el segundo y tercer modelo los valores fueron: OR $1,69,95 \%$ IC $1,18-2,41$ y OR $1,58,95 \%$ IC 1,12-2,23, respectivamente. En el último modelo, se asoció PCR elevada con una extensión de la pérdida de inserción clínica $\geq 3 \mathrm{~mm}$ (OR 1,58, IC 95\% 1,19-2,08). Los anticuerpos a Aa no se asociaron con niveles elevados de $\mathrm{PCR}$ en ningún modelo. Fibrinógeno alto (>400 mg/dl) tampoco se relacionó con Pg ni Aa.

Craig y cols. (22), determinaron el efecto del estado de la enfermedad periodontal y el progreso de los componentes de la respuesta de fase aguda en una población urbana minoritaria (185 descendientes afroamericanos, orientales-americanos e hispánicos) de Estados Unidos. Se presentó un incremento de IgG sérica a Pg pero no a otros cinco periodontopatóge- nos. Sin embargo, sí se observó mayor asociación con periodontitis avanzadas. En el análisis de regresión logística, los sujetos que presentaron múltiples sitios con periodontitis y niveles elevados de IgG a Pg aumentaron el OR significativamente. Estos resultados sugieren que la periodontitis y su progreso están asociados con cambios en los componentes séricos, consistentes con una respuesta de fase aguda.

Furiuchi y cols. (30), evaluaron la asociación del estado periodontal, empleando el índice CPITN (31), con las condiciones generales de salud y los títulos de anticuerpos séricos a Pg en una población japonesa constituida por 1.314 sujetos mayores de 40 años. El análisis de regresión logística multivariado reveló una asociación significativa entre los sujetos con presión sanguínea diastólica alta, nivel máximo CPITN-4 y niveles serológicos elevados de PCR (OR: 2,39). Se encontraron además, niveles séricos altos de IgG a Pg (OR: 1,54).

Renvert y cols. (32), estudiaron el papel de la infección periodontal y la carga bacteriana como variable explicativa de la activación del proceso inflamatorio que conduce al síndrome coronario agudo. Se estudiaron 161 casos diagnosticados con síndrome coronario agudo y 161 controles, pareados por género, nivel socioeconómico y hábito de fumar. La carga bacteriana oral fue mayor en los sujetos con síndrome coronario y significativo para $\mathrm{Pg}(\mathrm{p}<0,001)$. Los niveles elevados de PCR fueron factor explicativo del estado del síndrome coronario agudo $\left(r^{2}=0,49\right)$. Los autores concluyeron que la carga bacteriana de $\mathrm{Pg}$ puede ser factor de riesgo concomitante en el desarrollo de problemas coronarios.

Un estudio publicado recientemente (33), investigó el efecto de inoculaciones con Pg, repetidas sistémicamente, sobre la hiperplasia de la íntima en arterias ilíacas de un modelo animal. Una semana después de producir una dilatación a la arteria ilíaca, 30 conejos neozelandeses fueron asignados aleatoriamente a una inoculación semanal intravenosa con 100 microl de Pg ( $10^{7}$ unidades formadoras de colonia; $n=15$ ) o vehículo $(n=15)$, durante 4, 8 o 12 semanas consecutivas. En la semana 12, se aceleró la hiperplasia de la íntima en el grupo experimental. Igualmente los animales inoculados con Pg presentaron incrementos significativos en la infiltración por macrófagos y en los niveles de PCR. Los autores concluyeron que la Pg puede acelerar la hiperplasia de la íntima arterial en modelos animales.

Algunos estudios realizados en pacientes diabéticos tipo 2 con periodontitis crónica también han abordado la asociación entre Pg y PCR en ESI. Nishimura y 
cols. (34), estudiaron 131 sujetos japoneses no obesos con diabetes tipo 2 sin evidencia de enfermedad cardiovascular, isquemia cerebral, desordenes hepáticos, o falla renal crónica con el fin de investigar la asociación entre anticuerpos IgG contra Pg y niveles de PCR. Se observó una correlación entre PCR altamente sensible y títulos de anticuerpos IgG contra Pg FDC 381 y SU63 $(r=0,219, p<0,013$ y $r=0,233, p<0,008$, respectivamente). Los autores concluyeron que la infección periodontal es un factor que contribuye independientemente a futuros eventos cardiovasculares. Estos resultados son corroborados por Taniguchi y cols. (35), quienes investigaron la relación entre infección con Pg y el grado de aterosclerosis carótida en 134 sujetos diabéticos tipo 2 no obesos sin evidencia de enfermedad cardiovascular, isquemia cerebral, o falla renal crónica. Midieron el espesor de la íntima medial empleando ultrasonido de alta resolución en segmentos libres de placa ateromatosa de arterias carótidas comunes bilaterales. Además, se calculó el grado de estenosis en segmentos con placa en el mismo tipo de arterias. Los autores clasificaron los pacientes en dos grupos: uno con altos títulos de IgG contra Pg $(>310)$ y otro grupo con valores normales $(<310)$. Aunque el espesor de la íntima medial no fue diferente en los segmentos libres de placa ateromatosa entre los dos grupos, el grado de estenosis en los segmentos con placa fue significativamente más alto en el grupo con elevada IgG $(p=0,009)$. Con base en estos resultados, se concluyó que la infección con $\mathrm{Pg}$, aun cuando es una infección subclínica, se asocia con aterosclerosis vascular en pacientes no obesos diabéticos tipo 2. Kuroe y cols. (36), también investigaron la asociación entre periodontopatógenos (Pg, Aa, Prevotella Intermedius) y PCR en individuos no obesos diabéticos tipo 2 . Sus resultados apoyan las conclusiones de las dos investigaciones presentadas previamente: IgG contra Pg estuvo correlacionada con PCR ( $r=0,225, p<0,001)$, mientras que IgG contra Aa o P. Intermedius no presentó asociación.

Recientemente, también se ha estudiado la asociación entre Pg, PCR y otra enfermedad inflamatoria sistémica: la artritis reumatoide (AR). Mikuls y cols. (17), caracterizaron los anticuerpos a $\mathrm{Pg}$ en sujetos con $\mathrm{AR}$ $(n=78)$, periodontitis $(n=39)$, y en controles saludables $(n=40)$, explorando de esta forma su relación con enfermedades autoinmunes. Se examinó la correlación $\mathrm{Pg}$ con PCR y el factor reumatoide en sujetos con AR, y basados en la seropositividad a Pg, se comparó PCR con las concentraciones de anticuerpos. Fueron más comunes Pg elevados (títulos $>800$ ) a AR y a periodontitis comparado con los controles $(p=0,002)$. En AR se presentó una correlación entre Pg y PCR $(p=0,006)$. Los autores concluyeron que la asociación de Pg con anticuerpos relacionados con AR y PCR, sugiere que es fundamental la infección con estos microorganismos, en el riesgo y progreso de la AR. Igualmente, Liao y cols. (37), postularon recientemente que los anticuerpos a Pg están incrementados significativamente en pacientes con AR y que estos anticuerpos están correlacionados significativamente con anticuerpos antiCCP (péptido anticíclico), los cuales son específicos para AR. La infección bacteriana producida por Pg juega un papel importante en los péptidos y puede estar involucrada en la pérdida de auto-tolerancia, y desarrollo de autoinmunidad en AR.

Adicionalmente, también se han investigado estados avanzados de la inflamación sistémica como es la preeclampsia (PE) y amenaza de parto prematuro, y su asociación con Pg y PCR. Herrera y cols. (18), realizaron un estudio de casos y controles en 398 mujeres embarazadas, con el fin de analizar el efecto de la enfermedad periodontal en las concentraciones séricas de PCR y su asociación con PE. Pg fue el microorganismo más prevalente en mujeres con PE y presentaba una relación positiva con PCR $(p=0,01)$. Los autores concluyeron que los niveles de PCR fueron significativamente superiores en las mujeres con $P E$ y sus valores dependen de la agresividad de la infección periodontal. Por su parte, León y cols. (38), realizaron una evaluación periodontal en 26 mujeres con amenaza de parto prematuro (ocho con ruptura de membranas). Tomaron muestras microbiológicas de placa subgingival y líquido amniótico. Pg fue el periodontopatógeno encontrado con mayor frecuencia en el líquido amniótico y en las muestras de placa subgingival $(30,8 \%)$. De esta forma Pg puede activar las células Thl para que se secreten niveles altos de marcadores inflamatorios como PCR. Los autores concluyeron que la presencia de Pg en el líquido amniótico puede indicar una función periodontopatogénica en mujeres embarazadas con diagnóstico de amenaza de parto prematuro.

Es importante destacar que el diseño metodológico de las investigaciones presentadas anteriormente impide determinar una relación causal entre Pg, PCR y ESI, sin embargo, es evidente la asociación que se presenta.

\section{CONCLUSIONES}

Porphyromona gingivalis está asociada con incremento en los niveles de proteína-C Reactiva, indicando que la infección periodontal puede contribuir al aumento 
de cargas inflamatorias sistémicas en individuos saludables.

La infección periodontal medida por los niveles de anticuerpos a $P$ gingivalis y PCR es un fuerte predictor de enfermedades cardiovasculares.

La periodontitis y su progreso están asociados con cambios en los componentes séricos de PCR, consistentes con una respuesta de fase aguda.

No se ha encontrado asociación de $A$. actinomycetemcomitans y de $P$. Intermedius, con niveles elevados de PCR.

Los estudios realizados en pacientes diabéticos tipo 2 con periodontitis crónica han encontrado asociación entre Pg y PCR con enfermedad vascular aterosclerótica.

Es fundamental la infección con Pg y su asociación con anticuerpos relacionados con artritis reumatoide y PCR, en el riesgo y progreso de la AR.

Se ha documentado que Pg es el microorganismo más prevalente en mujeres con preeclampsia, presentándose correlación con PCR.

La presencia de Pg en el líquido amniótico puede indicar una función periodontopatogénica en mujeres embarazadas con diagnóstico de amenaza de parto prematuro.

\section{BIBLIOGRAFÍA}

1. Kuroe A, Taniguchi A, Sekiguchi A, Ogura M, Murayama Y, Nishimura F. Prevalence of periodontal bacterial infection in non-obese Japanese type 2 diabetic patients: relationship with C-reactive protein and albuminuria. Horm Metab Res 2004;36:116-8.

2. Pitiphat W, Savetsilp W, Wara-Aswapati N. C-reactive protein associated with periodontitis in a Thai population. J Clin Periodontol 2008;35:120-5.

3. Li L, Michel R, Cohen J, Decarlo A, Kozarov E. Intracellular survival and vascular cell-to-cell transmission of Porphyromonas gingivalis. BMC Microbiol 2008;8: 1-11.

4. Haynes WG, Stanford C. Periodontal disease and atherosclerosis: from dental to arterial plaque. Arterioscler Thromb Vasc Biol 2003;23:1309-11.
5. Yamazaki K, Honda T, Domon H, Okui T, Kajita K, Amanuma $\mathrm{R}$, et al. Relationship of periodontal infection to serum antibody levels to periodontopathic bacteria and inflammatory markers in periodontitis patients with coronary heart disease. Clin Exp Immunol 2007;149: 445-52.

6. Holt SC, Ebersole JL. Porphyromonas gingivalis, Treponema denticola, and Tannerella forsythia: the "red complex", a prototype polybacterial pathogenic consortium in periodontitis. Periodontol 2000 2005;38:72-122.

7. Offenbacher S, Boggess K A, Murtha AP, Jared HL, Lieff $\mathrm{S}, \mathrm{McKaig}$ RG, et al. Progressive periodontal disease and risk of very preterm delivery. Obstet Gynecol 2006;107:29-36.

8. Scannapieco F A. Pneumonia in nonambulatory patients. The role of oral bacteria and oral hygiene. J Am Dent Assoc 2006; 137:21S-5S.

9. Sheets SM, Robles-Price AG, McKenzie RM, Casiano CA, Fletcher HM. Gingipain-dependent interactions with the host are important for survival of Porphyromonas gingivalis. Front Biosci 2008;13:3215-38.

10. Hajishengallis G, Tapping RI, Harokopakis E, Nishiyama $S$, Ratti P, Schifferle RE, et al. Differential interactions of fimbriae and lipopolysaccharide from Porphyromonas gingivalis with the Toll-like receptor 2-centred pattern recognition apparatus. Cell Microbiol 2006;8: 1557-70.

11. Kinane DF, Galicia JC, Gorr SU, Stathopoulou PG, Benakanakere M.P. gingivalis interactions with epithelial cells. Front Biosci 2008;13:966-84.

12. Gibson FC 3rd, Yumoto H, TakahashiY, Chou HH, Genco CA. Innate immune signaling and Porphyromonas gingivalis-accelerated atherosclerosis. J Dent Res 2006;85:106-21.

13. Teragawa H, Fukuda Y, Matsuda K, Ueda K, Higashi Y, Oshima $\mathrm{T}$, et al. . Relation between $\mathrm{C}$ reactive protein concentrations and coronary microvascular endothelial function. Heart 2004;90:750-4.

14. Danielski M, Ikizler TA, McMonagle E, Kane JC, Pupim $\mathrm{L}$, Morrow J, et al. Linkage of hypoalbuminemia, inflammation, and oxidative stress in patients receiving maintenance hemodialysis therapy. Am J Kidney Dis 2003;42:286-94. 
15. Muntner P, Hamm LL, Kusek JW, Chen J, Whelton PK, He $\mathrm{J}$. The prevalence of nontraditional risk factors for coronary heart disease in patients with chronic kidney disease. Ann Intern Med 2004;140:9-17.

16. Bayes B, Pastor MC, Bonal J, Junca J, Hernandez JM, Riutort N, et al. Homocysteine, C-reactive protein, lipid peroxidation and mortality in haemodialysis patients. Nephrol Dial Transplant 2003;18:106-12.

17. Mikuls TR, Payne JB, Reinhardt RA, Thiele GM, Maziarz E, Cannella AC, et al. Antibody responses to Porphyromonas gingivalis (P.gingivalis) in subjects with rheumatoid arthritis and periodontitis. Int Immunopharmacol 2009;9:38-42.

18. Herrera JA, Parra B, Herrera E, Botero JE, Arce RM, Contreras $A$, et al. Periodontal disease severity is related to high levels of C-reactive protein in pre-eclampsia. J Hypertens 2007;25:1459-64.

19. Horton AL, Boggess KA, Moss KL, Jared HL, Beck J, Offenbacher $\mathrm{S}$. Periodontal disease early in pregnancy is associated with maternal systemic inflammation among African American women.J Periodontol 2008;79: 1127-32.

20. Tillet WS, Francis T. Serological reactions in pneumonia with a non-protein somatic fraction of pneumococcus. J Exp Med 1930;52:561-71.

21. Gabay C, Kushner I: Acute-phase proteins and other systemic responses to inflammation. N Engl J Med 1999;340:448-54.

22. Craig RG,Yip JK, So MK, Boylan RJ, Socransky SS, Haffajee AD. Relationship of destructive periodontal disease to the acute-phase response.J Periodontol 2003;74:1007-16.

23. Yue CC, Muller-Greven J, Dailey P, Lozanski G, Anderson V, Macintyre S. Identification of a C-reactive protein binding site in two hepatic carboxylesterases capable of retaining C-reactive protein within the endoplasmic reticulum. J Biol Chem 1996;271:22245-50.

24. Wu T, Dorn JP, Donahue RP, Sempos CT, Trevisan M. Associations of serum C-reactive protein with fasting insulin, glucose, and glycosylated hemoglobin: the Third National Health and Nutrition Examination Survey, 1988-1994. Am J Epidemiol 2002,155:65-71.

25. Cavrini F, Sambri V, Moter A, Servidio D, Marangoni A, Montebugnoli L, et al. Molecular detection of Treponema denticola and Porphyromonas gingivalis in carotid and aortic atheromatous plaques by FISH: report of two cases. J Med Microbiol 2005;54:93-6.

26. Lund Haheim L, Olsen I, Nafstad P, Schwarze P, Rønningen KS. Antibody levels to single bacteria or in combination evaluated against myocardial infarction. J Clin Periodontol 2008;35:473-8.

27. Pussinen PJ, Tuomisto $\mathrm{K}$, Jousilahti $\mathrm{P}$, Havulinna AS, Sundvall J, Salomaa V. Endotoxemia immune response to periodontal pathogens, and systemic inflammation associate with incident cardiovascular disease events. Arterioscler Thromb Vasc Biol 2007;27:1433-9.

28. Noack B, Genco RJ,Trevisan M, Grossi S,Zambon JJ,DeNardin E. Periodontal infections contribute to elevated systemic C-reactive protein level. J Periodontol 2001;72:1221-7.

29. Dye BA, Choudhary K, Shea S, Papapanou PN. Serum antibodies to periodontal pathogens and markers of systemic inflammation. J Clin Periodontol 2005; 32: 1189-99.

30. Furuichi $Y$, Shimotsu A, Ito $H$, Namariyama $Y$, Yotsumoto Y, Hino Y, Mishige Y, Inoue M, Izumi Y. Associations of periodontal status with general health conditions and serum antibody titers for Porphyromonas gingivalis and Actinobacillus actinomycetemcomitans. J Periodontol 2003; 74:1491-7.

31. Ainamo J, Barmes D, Beagrie G, Cutress T, Martin J, SardoInfirri J. Development of the World Health Organization (WHO) community periodontal index of treatment needs (CPITN). Int Dent J 1982;32:281-91.

32. Renvert S, Pettersson T, Ohlsson O, Persson GR. Bacterial profile and burden of periodontal infection in subjects with a diagnosis of acute coronary syndrome. J Periodontol 2006;77:1110-9.

33. Zhang MZ, Li CL, Jiang YT, Jiang W, Sun Y, Shu R, et al. Porphyromonas gingivalis infection accelerates intimal thickening in iliac arteries in a balloon-injured rabbit model. J Periodontol 2008;79:1192-9.

34. Nishimura F, Taniguchi A, Iwamoto Y, Soga Y, Fukushima $\mathrm{M}$, Nagasaka S, et al. Porphyromonas gingivalis infection is associated with elevated C-reactive protein in nonobese Japanese type 2 diabetic subjects. Diabetes Care 2002;25:1888.

35. Taniguchi A, Nishimura F, Murayama Y, Nagasaka S, Fukushima M, Sakai M, et al. Porphyromonas gingivalis infection is associated with carotid atherosclerosis in non- 
obese Japanese type 2 diabetic patients. Metabolism 2003;52:142-5.

36. Kuroe A, Taniguchi A, Sekiguchi A, Ogura M, Murayama Y, Nishimura F, et al. Prevalence of periodontal bacterial infection in non-obese Japanese type 2 diabetic patients: relationship with C-reactive protein and albuminuria. Horm Metab Res 2004;36:116-8.

37. Liao F, Li Z, Wang Y, Shi B, Gong Z, Cheng X. Porphyromonas gingivalis may play an important role in the pathogenesis of periodontitis-associated rheumatoid arthritis. Med Hypotheses 2009 Feb 24. [Epub ahead of print].
38. León R, Silva N, Ovalle A, Chaparro A, Ahumada A, Gajardo M, et al. Detection of Porphyromonas gingivalis in the amniotic fluid in pregnant women with a diagnosis of threatened premature labor. J Periodontol 2007;78:1249-55.

\section{CORRESPONDENCIA}

Carlos Martín Ardila Medina

Carrera 47 No. 20 sur 46 Envigado Antioquía Colombia 57(4) 3348122

cmartin@odontologia.udea.edu.co 